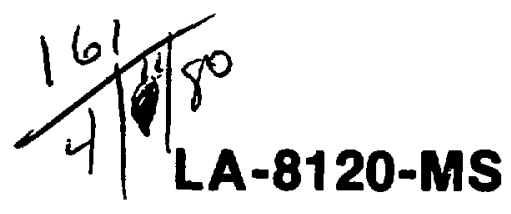

Informal Report

\title{
MASTER
}

\section{The Effects of Drop Testing on Scale Model Shipping Containers Shielded with Depleted Uranium}


THE EFFECTS OF DROP TESTING ON SCALE MODEL SHIPPING

CONTAINERS SHIELDED WITH DEPLETED URANIUM

by

Thomas A. Butler

\begin{abstract}
Three scale model shipping containers shielded with depleted uranium were dropped onto an essentially unyielding surface from various heights to determine their margins to failure. This report presents the resuits of a thorough posttest. examination of the models to check for basic structural integrity, shielding integrity, and deformations. Because of unexpected behavior exhibited by the depleted uranium shielding, several tests were performed to further characterize its mechanical properties. Based on results of the investigations, recommendations are made for improved container design and for applying the results to full-scale containers. Even though the specimens incorporated specific design features, the results of this study are generally applicable to any container design using derleted uranium.
\end{abstract}

\title{
I. INTRODUCTION
}

During May 1979, the Departinent of Energy (DOE) sponsored an extensive test program at the Los Alamos Scientific Laboratory (LASL) to determine the failure threshold of typical radioactive material shipping containers. ${ }^{1}$ The tests were performed jointly by LASL and the Battelle Columbus Laboratories (BCL). Scale model specimens were used to avoid the cost of destroying full-scale containers. The models were designed by $\mathrm{BCL}$ to incorporate features of several types and styles of containers used over the past decade. However, they are not true replica models of any single container. Of the 18 models tested, 15 
were lead shielded and 3 were shielded with depleted uranium alloyed with $2 \%$ molybdenum by weight (U-2Mo).

Maximum benefit from any destructive test is realized only through a thorough posttest examination and analysis of the test specimens. With such examinations, possible failures can be located and then verified. A thorough investigation of each failure can lead to its cause and thus to recommendations for improved designs and improved protection for existing designs. When such information is lacking, critical materials should be characterized to provide data for explaining test results and for improving mathematical models of the tests specimens. To achieve this maximum benefit, we performes an extensive posttest examination of the U-2Mo shielded models while $\mathrm{BCL}$ investigated those shielded with lead.

Our investigations of the U-2Mo shielded models were performed in two phases--predisassembly and postdisassembly. Before the models were disassembled, geometrical measurements were taken, and then the models were subjected to a radiographic examination to determine if the U-2Mo fractured and to gain information on internal deformations. Finally, dye-penetrant checks were performed on all exposed welds. In the postdisassembly phase, we performed visual inspections, took geometrical measurements, radiographed and performed dyepenetrant checks on severely stressed segments of U-2Mo, performed mechanical tests on the U-2Mo, and examined welds.

This report presents the results of each of the posttest examinations and our recommendations for improving container designs based on the results.

\section{DESCRIPTION OF TESTS}

Two of the U-2Mo models are 1/8-scale, and one is a 1/4-scale representation of a full-size truck container. Each model is made of an outer and an inner stainless steel she11. Between these two shells are eight cylindrical segments of U-2Mo. The bottom segment has a circular plate of U-2Mo pressed into it. The top of the container has a cover held onto the model by six bolts. A single 0-ring provides the seal for the cover. Table I gives dimensions for components of the two sizes of models. Review of several of the figures shown later in this report should provide a good concept of the container structure.

Each model was dropped such that it struck a stee 1 impact pad with the bottom end first at an angle of $30^{\circ}$ from the horizontal. The 1/4-scale model 
TABLE I

NOMINAL DIMENSIONS OF MODEL COMPONENTS (IN.)

\author{
Measurement \\ Outer shell thickness \\ Inner shell thickness \\ Inner cavity diameter \\ U-2Mo thickness \\ Overall model length (without cover) \\ Overall model diameter \\ U-2Mo segment length \\ $\mathrm{U}-2 \mathrm{MO}$ end plate thickness
}

1/4-scale model

0.280

0.065

4.33

0.800

46.602

6.62

5.919

0.593 $\underline{1 / 8 \text {-scale model }}$

0.120

0.035

2.157

0.511

23.305

3.50

2.960

0.322

and one 1/8-scale motel (designated Models $C$ and $A$, respectively) were dropped through a height of $30 \mathrm{ft}$. The other $1 / 8$-scale mode 1 (Model B) was dropped $70 \mathrm{ft}$. Each model bowed somewhat at primary impact and then was more severely bowed at the secondary impact. Figure 1 shows a sequence of frames taken from a high-speed film record of the test involving Model B. Note from the figure that most of the bowing occurred at secondary impact. Both 1/8-scale models lost the ir covers at secondary impact. This should not be considered a significant data point because the cover bolts were scaled geometrically, but were made from iow-strength material. The cover stayed on the 1/4-scale model, which had higher strength bolts. Several drops of the dye held in the inner cavity came out at impact, but the cover apparently resealed. No further leakage was noted when the model was held upside down for several hours.

\section{CONTAINER DEFORMATION}

Figures 2--10 show the three models part way through posttest disassembly. The three most prominent features of overall container deformation are seen in the figures to be container bowing, local deformation of the stainless steel outer shell near the initial impact point, and ovaling of the model cross section on the secondary impact end. Very little local deformation of the U-2Mo, including ovaling, occurred on the primary impact end. The difference in deformation on the two ends is due in part to the U-2Mo circular plate pressed into the end of the bottom U-2Mo segment. Another factor is that the secondary 
TABLE II

INTERNAL DIAMETER OF U-2MO SEGMENTS AFTER DROF TESTS ${ }^{\mathrm{a}}$

\begin{tabular}{cllccc} 
Model & Segment & End & $\begin{array}{c}\text { Angle from Vertical } \\
\text { Plane (degrees) }\end{array}$ & $\begin{array}{c}\text { Internal Diameter } \\
\text { (in.) }\end{array}$ \\
\cline { 1 - 1 } A & Bottom & Upper & 0 & 2.228 \\
A & Bottom & Upper & 90 & 2.228 \\
A & Top & Upper & 0 & 2.186 \\
A & Top & Upper & 90 & 2.252 \\
A & Top & Lower & 0 & 2.225 \\
A & Top & Lower & 90 & 2.228 \\
B & Bottom & Upper & 0 & 2.182 \\
B & Bottom & Lower & 0 & 2.193 \\
B & Top & Upper & 0 & 2.116 \\
B & Top & Upper & 90 & 2.296 \\
B & Top & Lower & 0 & 2.185 \\
B & Top & Lower & 90 & 2.232 \\
C & Bottom & Upper & 0 & 4.463 \\
C & Bottom & Upper & 90 & 4.464
\end{tabular}

aNominal internal diameter before testing was 2.227 in. for Models $A$ and $B$ and 4.460 in. for Model C.

impact point strikes the pad with 1.5--2.0 times the velocity at which the primary impact point strikes the pad. A third factor on Models $A$ and $B$ is that for both specimens the cover came off at secondary impact and therefore considerably reduced the radial constraint on the upper end. Table II gives information on ovaling for several of the U-2Mo segments removed from the models.

For all three models, the bowing was produced by stretching of the outer stainless steel shell while the U-2Mo segments remained essentially undeformed. Evidence from paint cracking on the outer surface of the containers indicated that the highest str $_{i} i_{1}$ in the outer shell were localized near the intersections of the U-2MO s. jmen.s. Figures 11 and 12 show posttest radiographs taken of Models $A$ and $B$ in a direction perpendicular to the plane in which they were dropped. Gaps between U-2Mo segments introduced by the bowing can be clearly seen in these figures. Table III gives the maximum gap widths at the segment 
TABLE III

GAP WIDTH AT OUTER EDGE OF U-2MO SEGMENTS (IN.)

\begin{tabular}{|c|c|c|c|}
\hline Joint $^{a}$ & Model A & Mode1 B & Model C \\
\hline 1 & 0.016 & 0.008 & 0.016 \\
\hline 2 & 0.059 & 0.035 & 0.031 \\
\hline 3 & 0.055 & 0.138 & 0.063 \\
\hline 4 & 0.047 & 0.106 & 0.063 \\
\hline 5 & 0.012 & 0.063 & 0.031 \\
\hline 6 & 0.008 & 0.012 & 0.004 \\
\hline 7 & 0.004 & 0.008 & 0.004 \\
\hline
\end{tabular}

a Joints are numbered from the cover end.

interfaces for each model, and Table IV gives the amount of bowing experienced by each model measured as maximum permanent deflection of the model centerline.

IV. STRUCTURAL INTEGRITY OF OUTER SHELL

The stainless steel outer shells remained intact except for the corner welds at the impact points. Figure 13 shows that for Model B the weld metal completely separated exposing the corner of the U-2Mo. Posttest dye-penetrant checks of the three models indicated at least some weld damage occurred on each one. Results of these checks are presented in Figs. 14, 15, and 16.

After posttest disassembly, metallographic samples were taken from the corner welds at the bottom (initial impact end) of each of the three models. One sample was taken from each at the initial impact point where dye-penetrant checks indicated some damage. A second sample was taken from the same weld on

TABLE IV

MODEL BOWING

$\begin{array}{cc}\text { Model } & \text { Bow (in.) } \\ & 0.28 \\ B & 0.56 \\ C & 0.38\end{array}$
each model but at a point $180^{\circ}$ from the initial impact point. These samples were essentially undisturbed. The samples were polished and investigated for damage.

Figure 17 shows the undisturbed weld from Model $B$ and the two sides of the weld that completely separated at 
the initial impact point. Note that the original weld completely penetrated the parent metal. The joint separation is completely within the weld material. This is not surprising because the weld is at the point of maximum damage. It was severely crushed and then strained in shear from the inertial load of the U-2Mo shielding material pushing down on the bottom end plate of the container. Even though the separation was in the weld metal, it has the characteristics of a ductile failure. This is best seen by noting the extreme deformation that took place in the weld metal.

Weld samples from Models $A$ and $C$ are shown in Fig. 18. The figure shows that weld penetration was not complete for either model. Both models show slip lines at nearly the same location where the metal separated in Model B. The shape of the metal on either side of the slip line from Model A compares close$1 y$ with the equivalent separated sides from Model B.

\section{EXAMINATION OF U-2Mo}

Mechanical properties tests performed by the manufacturer on castings from which the U-2Mo segments came indicated elongations ranging from 5.5\% to $16.0 \%$ and reductions in area from $5.4 \%$ to $22.2 \%$. Reference 2 gives mechanical properties for U-2Mo taken from a separate set of castings. Data in that reference indicate an average elongation of $9.7 \%$ at room temperature during quasistatic tests. For a strain rate of $10 \mathrm{in./in./s,} \mathrm{this} \mathrm{value} \mathrm{went} \mathrm{to} 8.3 \%$. Charpy $V$-notch tests indicated the material is brittle to at least $200^{\circ} \mathrm{F}$. Because of its brittle nature, we examined the material thoroughly to determine whether it remained intact during the drop tests.

Visual examinations of the shielding material indicated that very little deformation occurred except for ovaling of the upper end from $e_{\text {: }}$ model. Also, no cracks were in evidence except for shallow circumferential cracks that apparently extend only through an outer layer of corroded material.

To insure that no cracks were present that we could not see during the visuat inspection, we took radiographs of the end segments from Models $A$ and $B$ and the bottom segment from Model $C$ and performed dye-penetrant checks on the same segments. The top segment from Model $C$ could not be removed from the stainless steel shell. Results of the radiographs are shown in Figs. 19--23. Before the radiographs were taken, we cut the bottom segment from Model $B$ in half longitudinally. We believed that this was the segment most likely to 
fracture and that better radiographs would result if they were taken through only cne thickness of the segment. No cracks were found in any of the segments. However, considerable porosity existed in several of them. Note especially at the middle of segment B-1-2 (Fig. 21) a long slender void is present that could possibly provide a natural nucleation point for a fracture. However, all subsequent radiographic examinations and dye-penetrant tests showed no evidence of cracks. Porosity in the segments ranges from quite high (Figs. 21 and 23) to none that can be detected (Fig. 19) with the 23 Mev Betatron machine used to take the radiographs. We feel that this large difference in porosity could account for some of the large differences in mechanical properties. The dye-penetrant checks showed nothing except for the circumferential surface cracks (Fig. 24) that were identified during the visual examination.

Based on materials properties that were available for U-2Mo (Refs. 1 and 2) and the estimated strains that occurred, we determined that further characterization of the material should be done to explain its behavior. We machined Charpy V-notch specimens from Models $A$ and $C$ to determine the ductile-tobrittle transition temperature for the U-2Mo actually used in the models. The specimens were purposely taken from segments with minimum porosity to make the results as consistent as possible.

Specimens taken from Model A were oriented in the longitudinal direction, and those from Model $C$ were oriented in the tangential direction. Results are shown in Fig. 25. The impact energy values are consistent with those reported for U-2Mo in Ref. 2 for a different casting of the same material.

Use of the Charpy V-notch specimen is not the ideal method for determining ductile-to-brittle transition temperatures or for inferring information on fracture toughness. References 3 and 4 give several reasons why this specimen is not totally appropriate for analyzing steel. We believe that the same reasons apply to the U-2Mo material. One point is that the Charpy specimen is significantly smaller than the U-2Mo r,ross section (especially for Model C). Data show that in the size range of the U-2Mo cross section, $t$ is transition temperature is quite sensitive to specimen thickness. Also, the specimen is small enough that microstructural metallurgical parameters affect its response more than mechanical parameters such a yield stress.

The Dynamic Tear (DT) specimen has become a more acceptable method for obtaining the transition temperature and fracture toughness data. The physical size of the U-2Mo segments precluded using the DT specimen directly. However, 
we were able to obtain some information relating Charpy $V$-notch data to DT data for unalloyed depleted uranium. The results are shown in Figs. 26 and 27 . The toe of the ductile-to-brittle transition curve is difficult to pinpoint exactly, but it appears to curve from $70^{\circ} \mathrm{F}$ or less on the Charpy curve to $195^{\circ} \mathrm{F}$ on the DT curve. A similar trend is expected for the U-2Mo. This indicates that the U-CMo is certainly brittle through the complete temperature range of interest. Based on the Charpy data, we expect little difference in the behavior of the U-2Mo at room temperature (RT) and very low temperatures.

Reference 2 gives values of $\mathrm{K}_{I C}$, or fracture toughness, for a range of temperatures from $-40^{\circ} \mathrm{F}$ to $400^{\circ} \mathrm{F}$. From $-40^{\circ} \mathrm{F}$ to $\mathrm{RT}$ the value changes

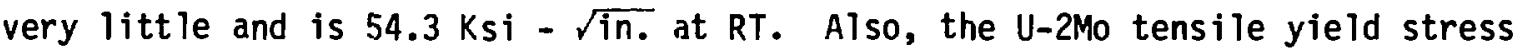
is fairly insensitive to temperature from $-40^{\circ} \mathrm{F}$ to $R T$. Its value at RT is $67.1 \mathrm{Ksi}$. Though the material is apparently quite brittle at RT (based on Charpy $V$-notch tests), its fracture toughness is reasonably high.

A measure of how a specified thickness of the material behaves under tensile conditions is provided by the parameter $\beta$, where

$$
\beta=\frac{1}{B}\left(K_{I C} / \sigma_{y s}\right)^{2}
$$

In this formula $B \equiv$ specimen thickness, $K_{I C} \equiv$ fracture toughness, and $\sigma_{y s} \equiv$ yield stress in simple tension. The plane strain limit, where fracture would occur before any significant plastic yielding, generally occurs for $\beta \leq 0.4$. This limit is generally used to choose the minimum thickness of compact tension fracture toughness specimens used for determining $K_{I C}$ values. The value of $\beta=1.0$ is the upper limit for elastic-plastic characteristics and for $\beta>1.0$, under a tensile load, through-thickness yielding will occur before a crack's growth becomes unstable. For U-2Mo the thickness $(B)$ is 0.66 in. or less for $B \geq 1.0$, and it is 1.64 or greater for $B \leq 0.4$. Based on the thickness of the U-2Mo in Models $A$ and $B(0.511$ in.), the U-2Mo will yield before brittle fracture occurs. The thickness of Model $C(0.800 \mathrm{in}$.$) indicates that it is in the$ transition elastic-plastic zone. However, for the type of deformation the U-2Mo undergoes (ovaling of the segments), the segment cross section is in bending, and only half its thickness would be in tension. If only the bending stresses are considered, the tensile stress would vary from 0.0 at the crosssection centerline to a maximum at the outer edge. Therefore, the effective 
thickness is less than 0.80 in., and significant plastic yielding would probably be expected before fracture.

The maximum amount of strain experienced by any U-2MO was estimated to be 10-15\%. Reference 2 gives an average elongation during dynamic tests (strain rate of $10.0 \mathrm{in./in./s)} \mathrm{of} 8.3 \%$. Manufacturers' data indicate elongations up to $16.0 \%$. Therefore, it is not surprising that the material did not fracture.

\section{CONCLUSIONS AND RECOMMENDATIONS}

From the results of our posttest examination we have drawn conclusions that lead to the following recommendations. For controlling overall container deformation we suggest that the stainless steel thickness be increased. Locking the U-2Mo segments together would decrease container bowing, but this is not recommended because the shielding could fracture under the additional tensile loads that it would experience with that design.

The structural integrity of the outer shell would be significantly improved if the welds were kept away from the corners. This could be accomplished by forming a bottom cover with short sides on it that could be welded to the outer cylindrical shell above the corner. The high corner loads would then be taken by the stainless steel, which has a higher ductility than the weld metal and also has more predictable and consistent behavior. When the closure welds are made on the outer she11, full penetration welds should be achieved, but care should be taken that no alloying takes place with the U-2Mo, which would considerably weaken the weld. Also, the weld joints would probably be improved by using type $304 \mathrm{~L}$ rather than 304 stainless steel. Cutting action of the U-2Mo segments on the outer shell could be alleviated by rounding or chamfering the corners of the shielding material.

Extension of the effects of the drop test on the U-2Mo from the models to full-scale containers is difficult. Because thickness effects on the fracture characteristics are critical, the U-2Mo might behave completely differently in full-scale containers under the same test conditions. Before more conclusions about the response of the U-2Mo can be drawn, we recommend that further characterization of the material be dont. This should include obtaining mechanical properties for higher strain rates and obtaining fracture toughness data for whicker cross sections than used in Ref. 2 to assure that plane strain effects are included. 
ACKNOWLEDGIUENTS

I thank Thomas I. Jones and others in LASL Group CMB-6 for performing the materiais characterization tests and for investigacing the welded joints from the specimens. I also acknowledge LASL Group M-1 for performing the dyepenetrant tests and for taking the radiographs.

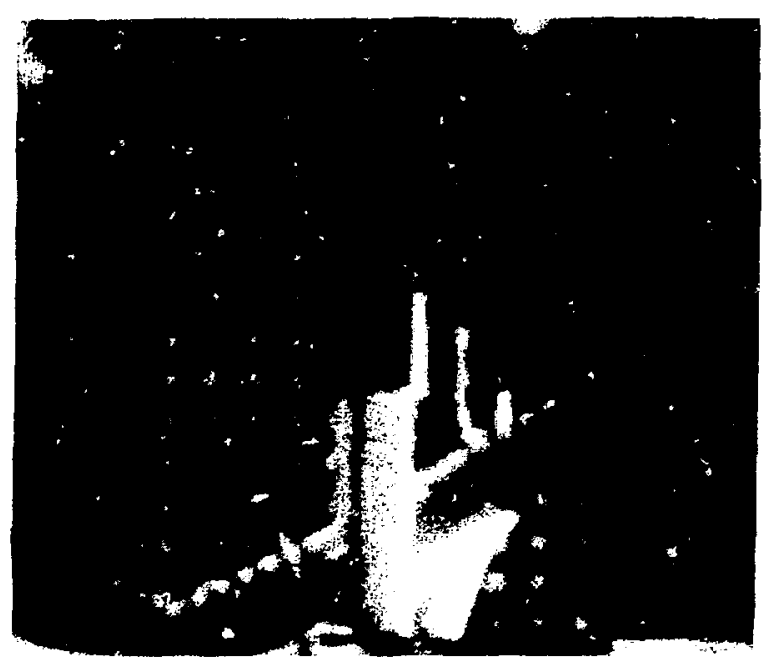

Primary impact.

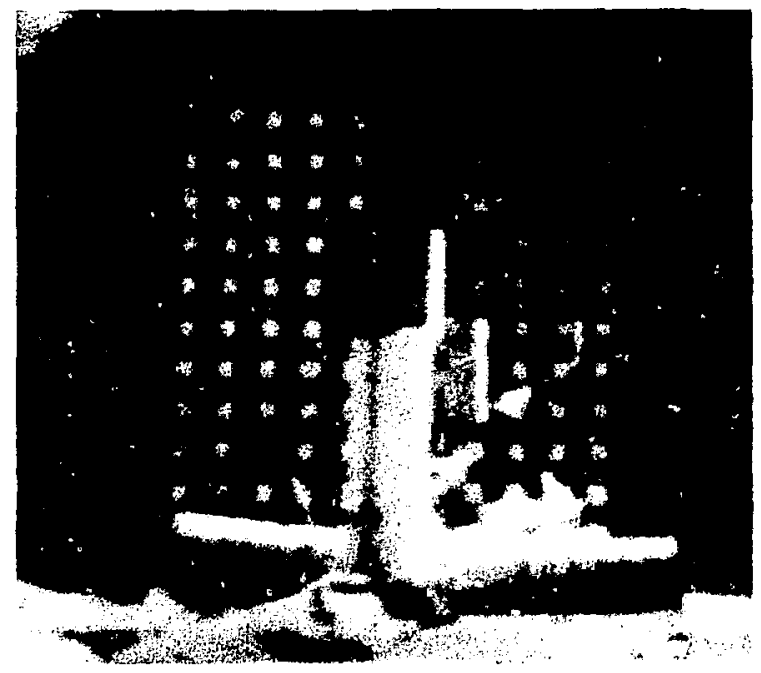

Secondary impact.

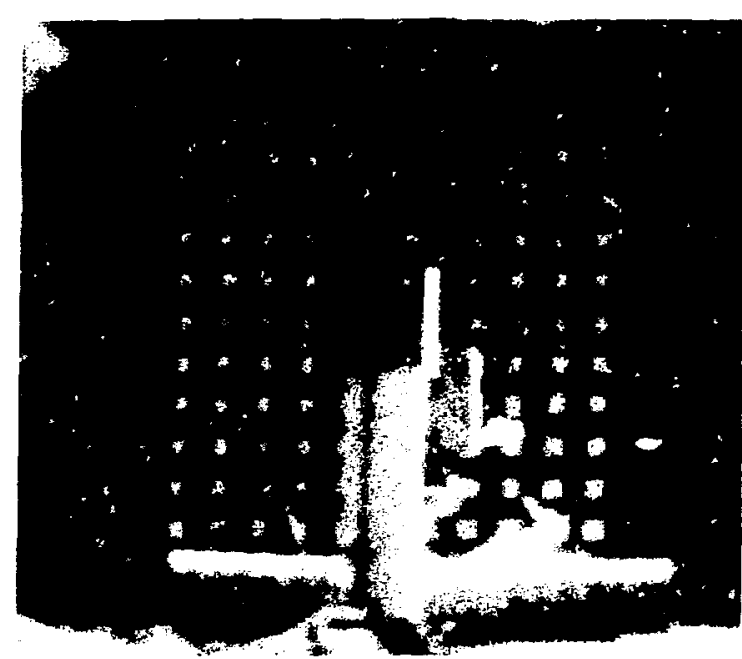

After primary impact.

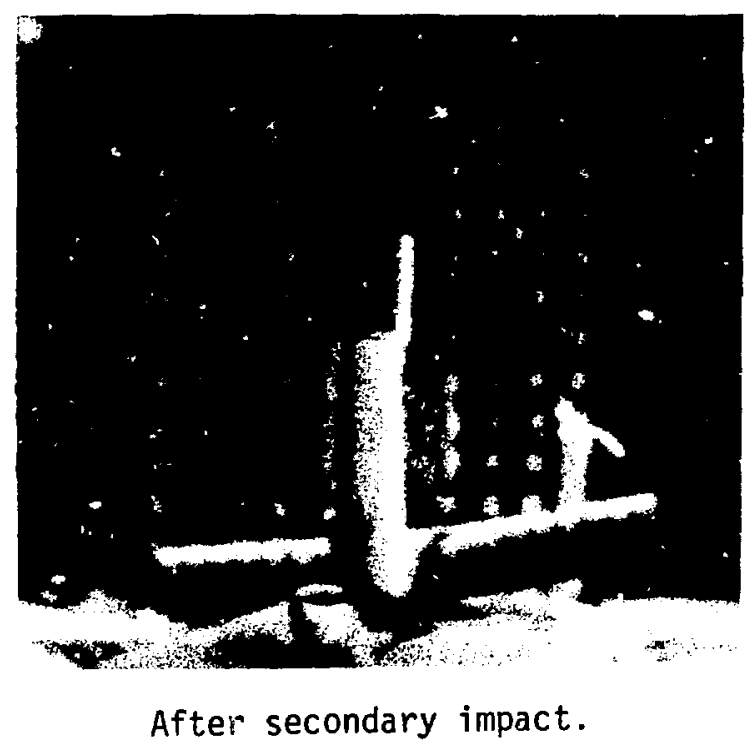

Fig. 1 .

Response of 1/8-scale model to primary-through-secondary impact. 


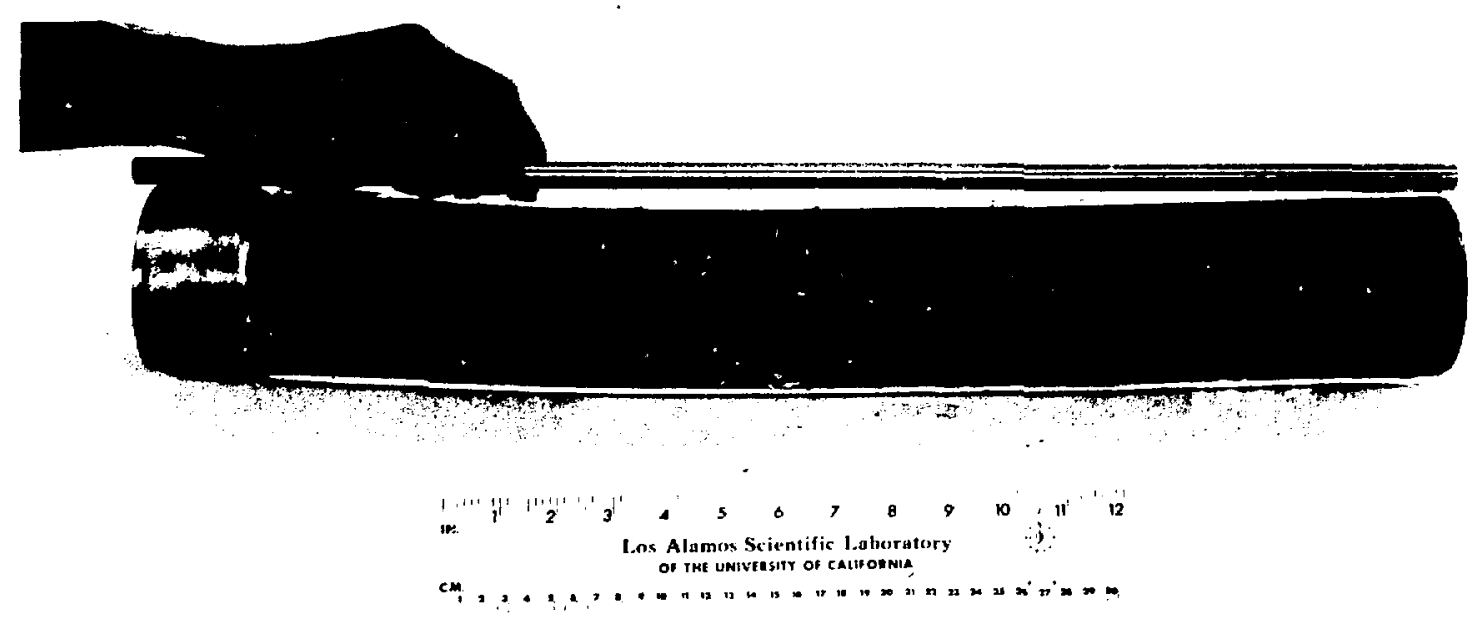

Fig. 2 .

Model A side view after outer shell removal.

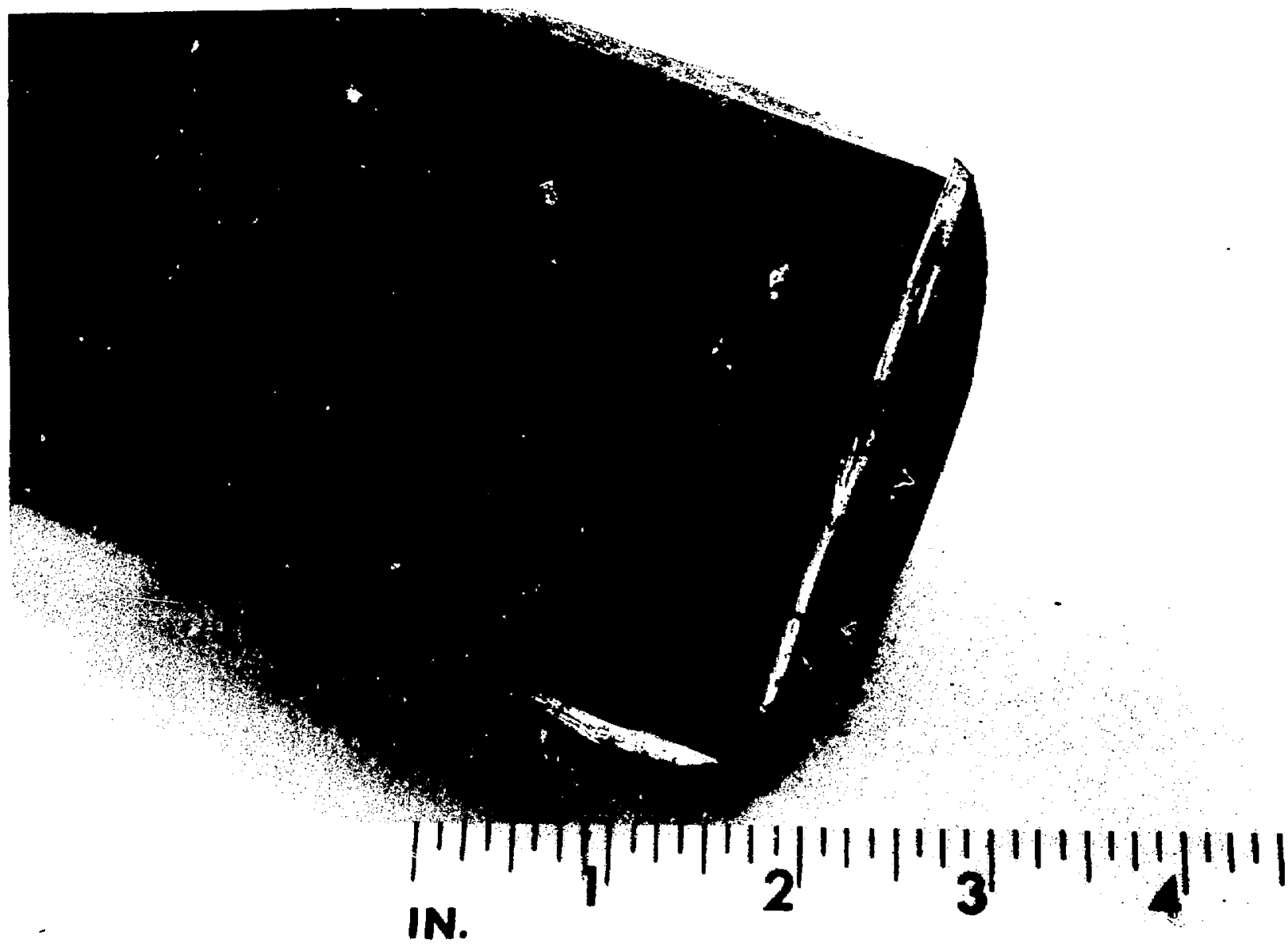

Fig. 3.

Model A primary impact end. 


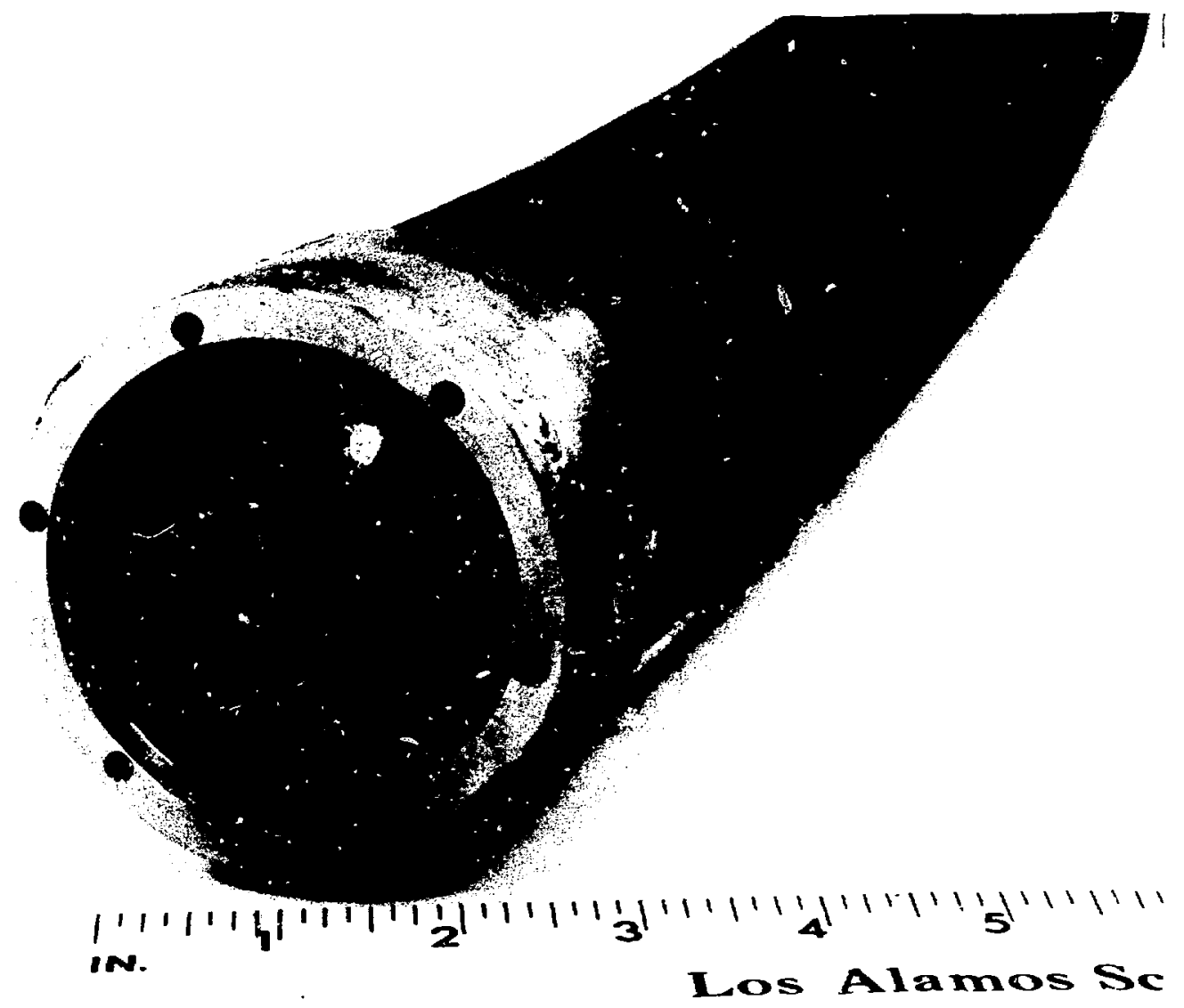

Fig. 4.

Model A secondary impact end.

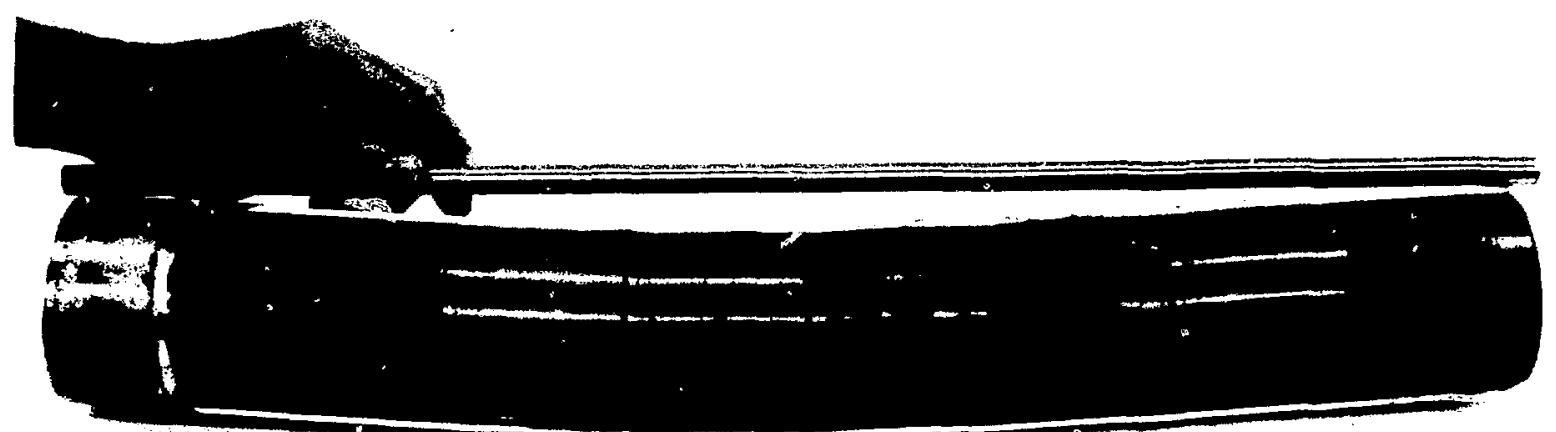

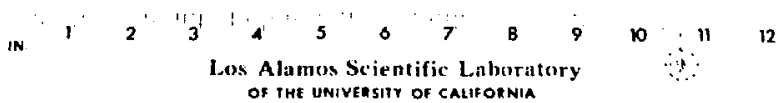

Fig. 5.

Model B side view after outer shell removal. 


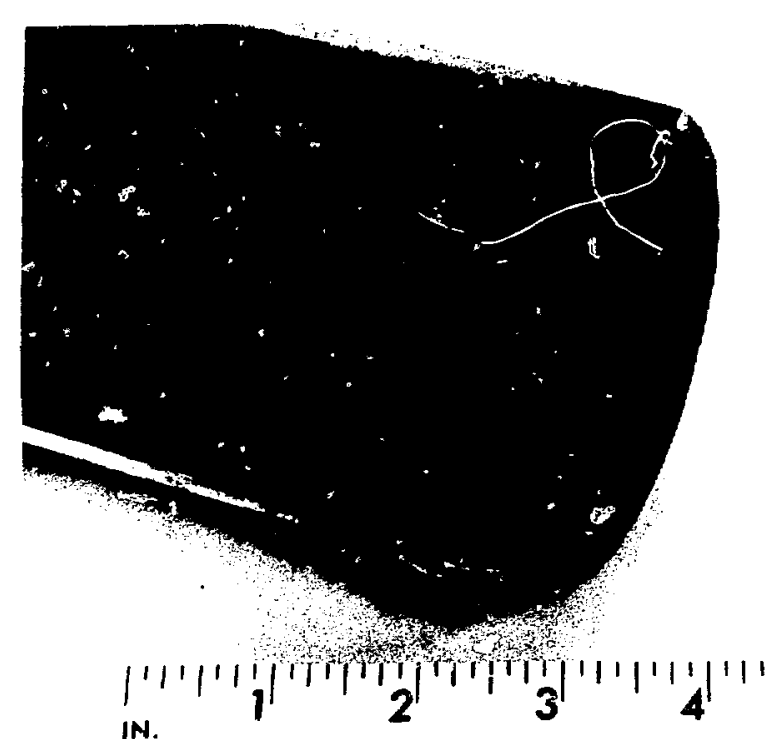

Fig. 6 .

Model B primary impact end.

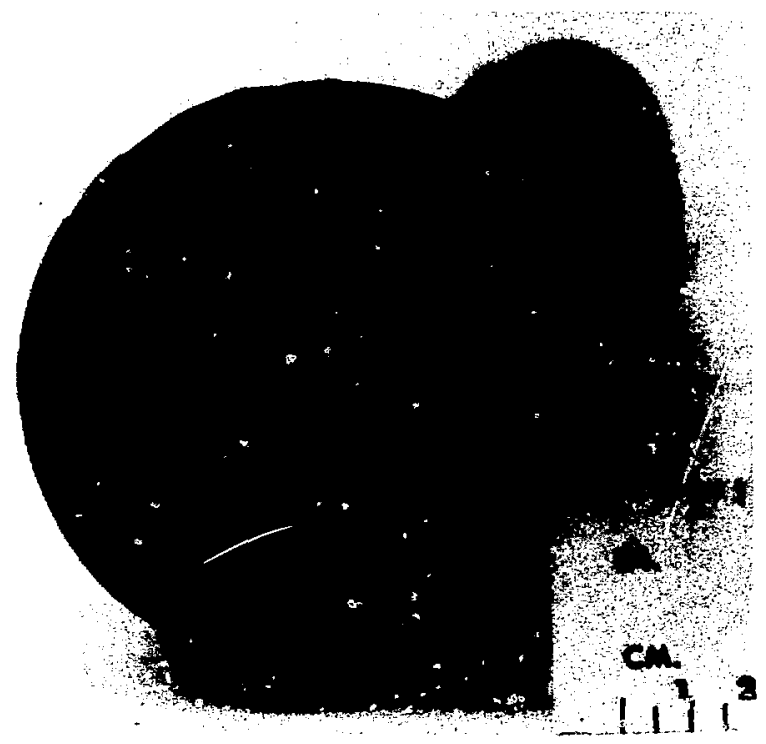

Fig. 7. ilodel B secondary impact end.

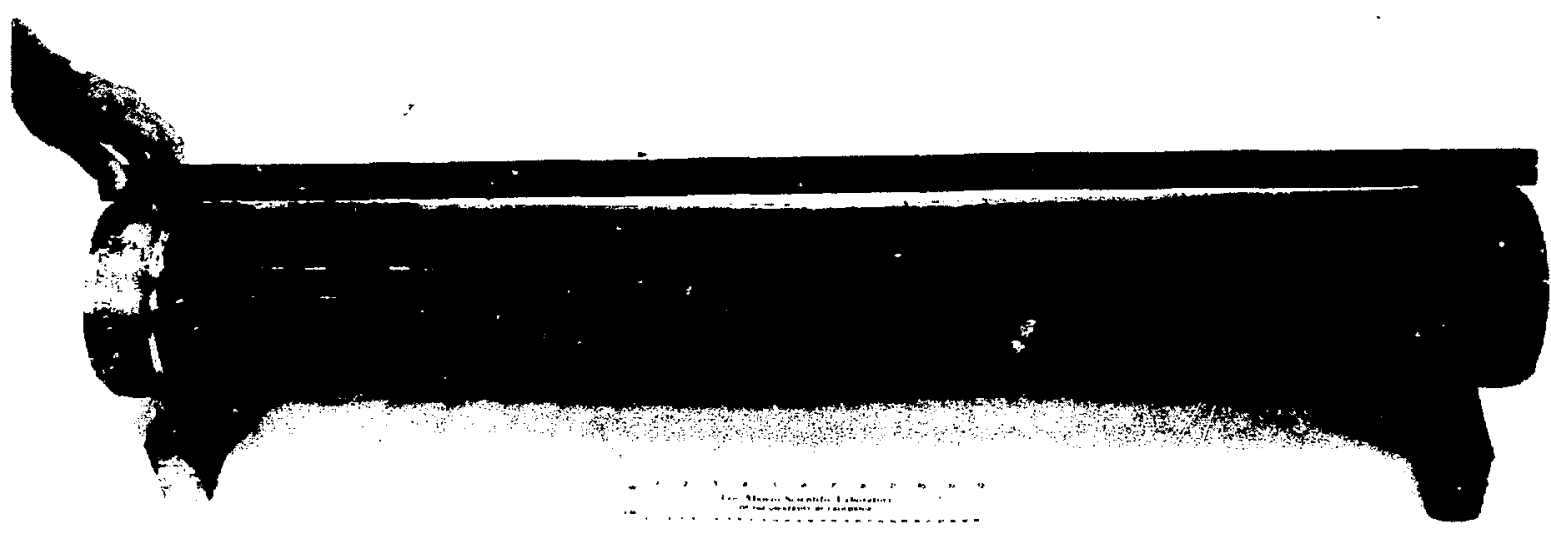

Fig. 8.

Model $\mathrm{C}$ side view after outer shell removal. 


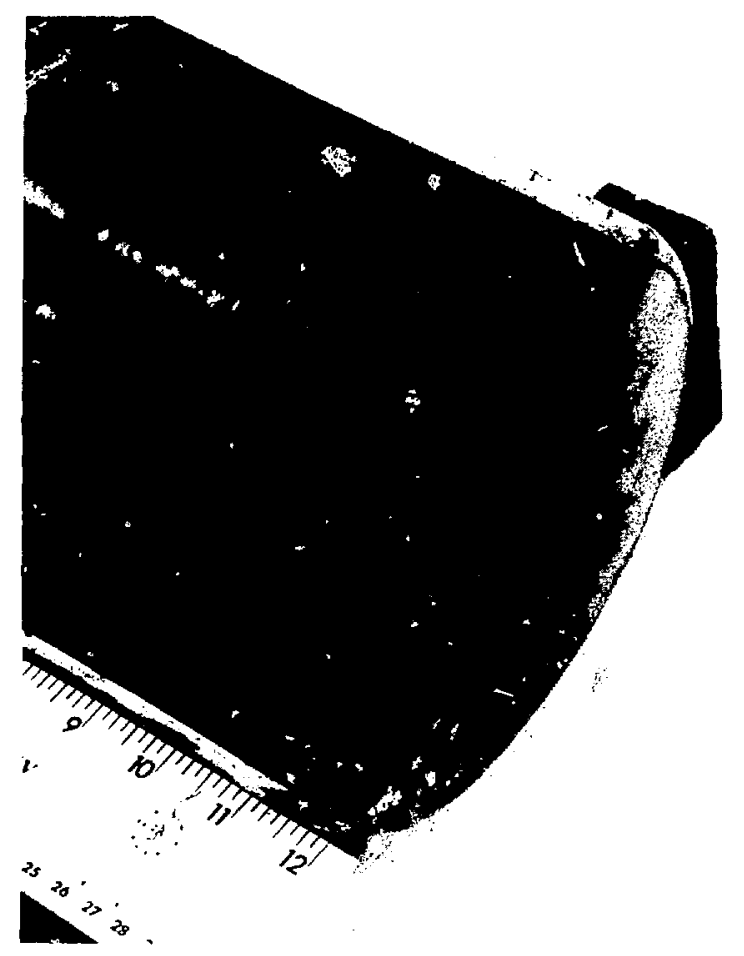

Fig. 9.

Model C primary impact end.

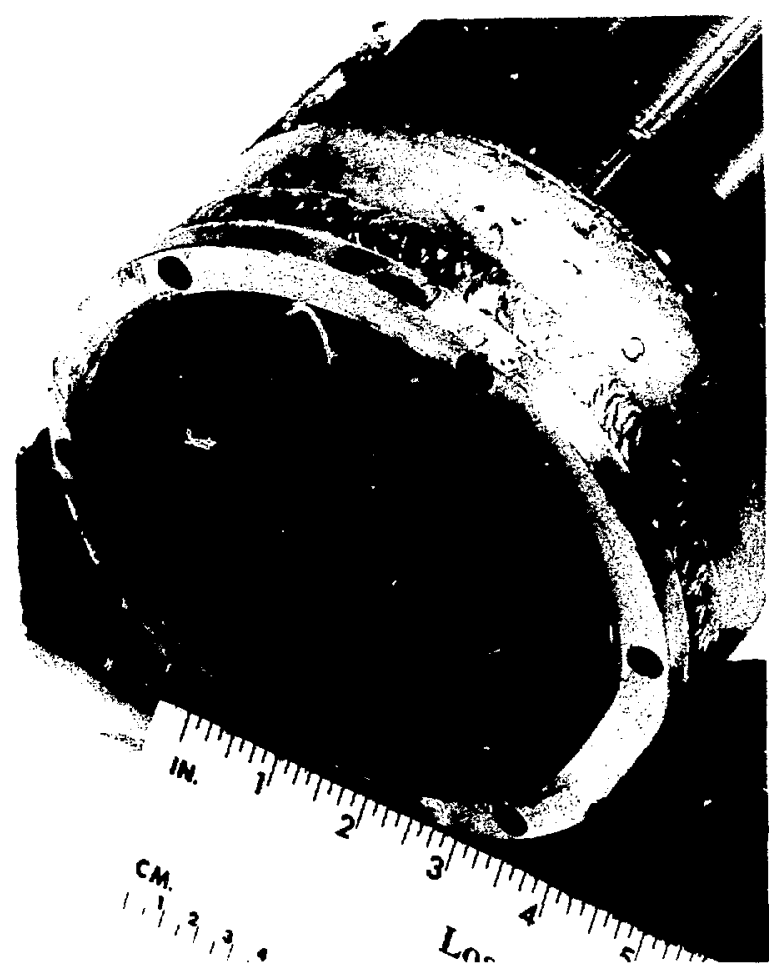

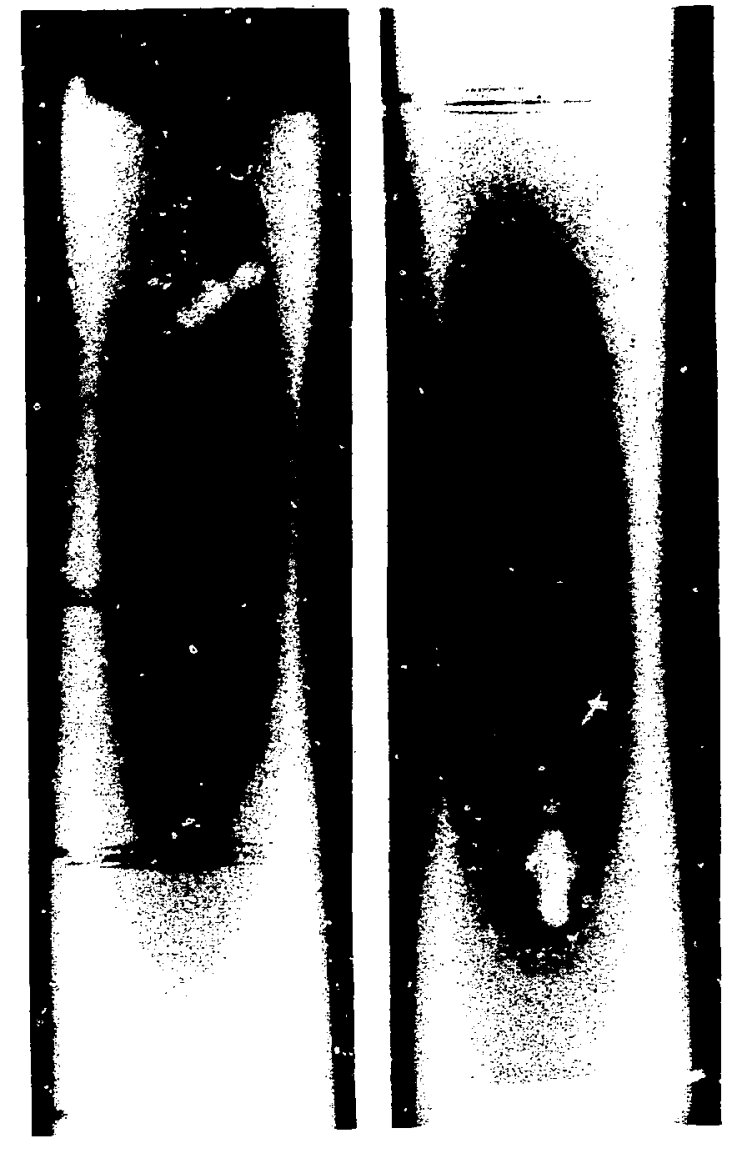

Top Part

Bottom Part

Fig. 11.

Predisassembly radiograph of Model $A$.

Fig. 10.

Model $C$ secondary impact end. 


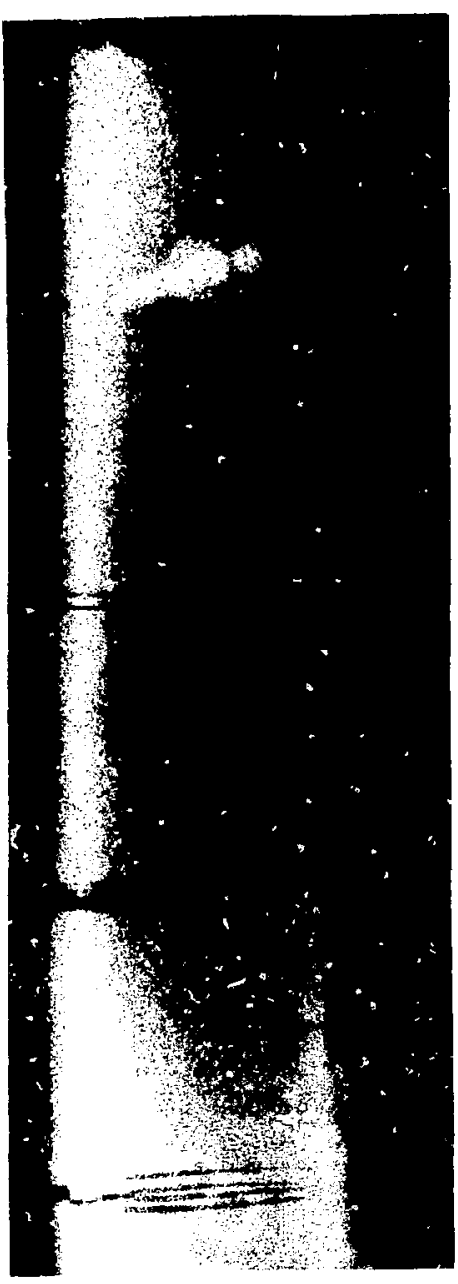

Top Part

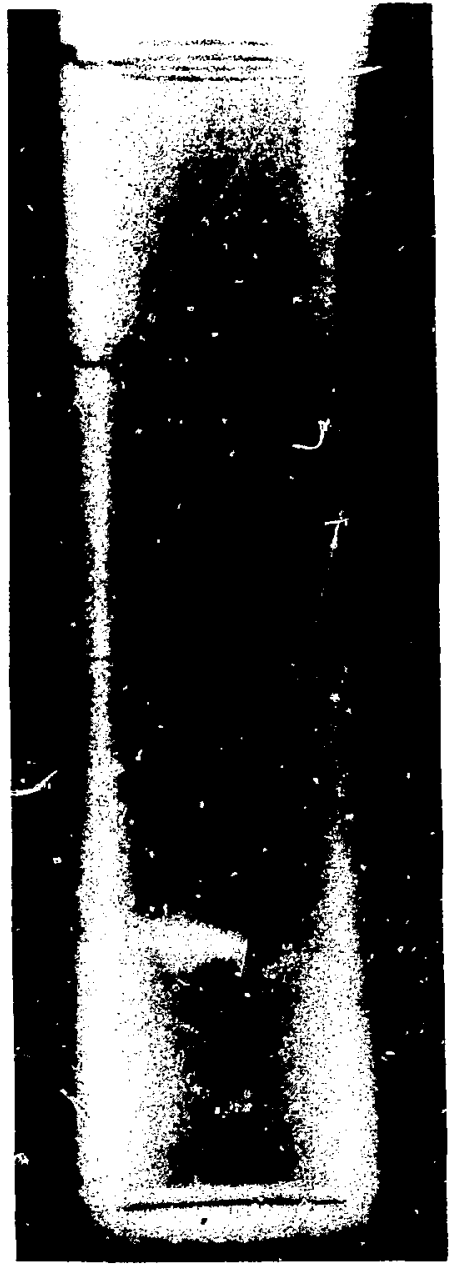

Bottom Part
Fig. 12 .

Predisassembly radiograph of Model $B$.
Fig. 13.

Weld damage on Model $B$ at primary impact point.

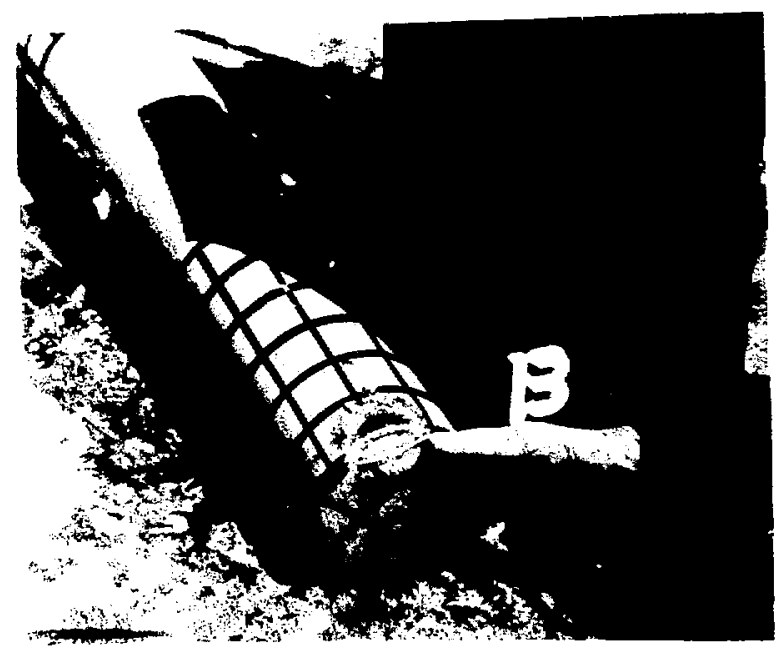




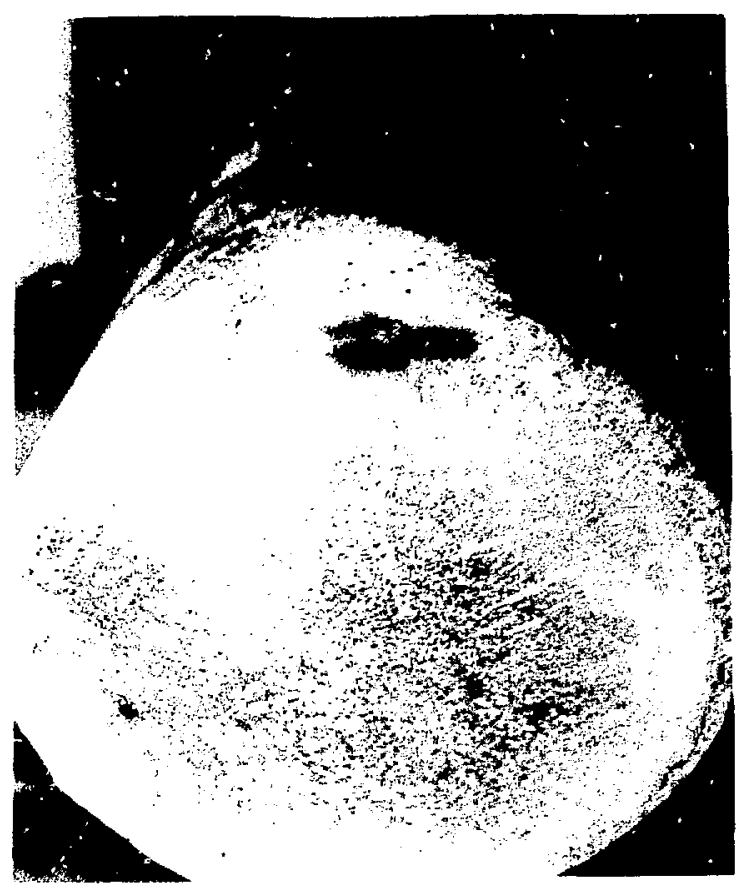

Fig. 14.

Results of posttest dye-penetrant check of bottom weld on Model A.
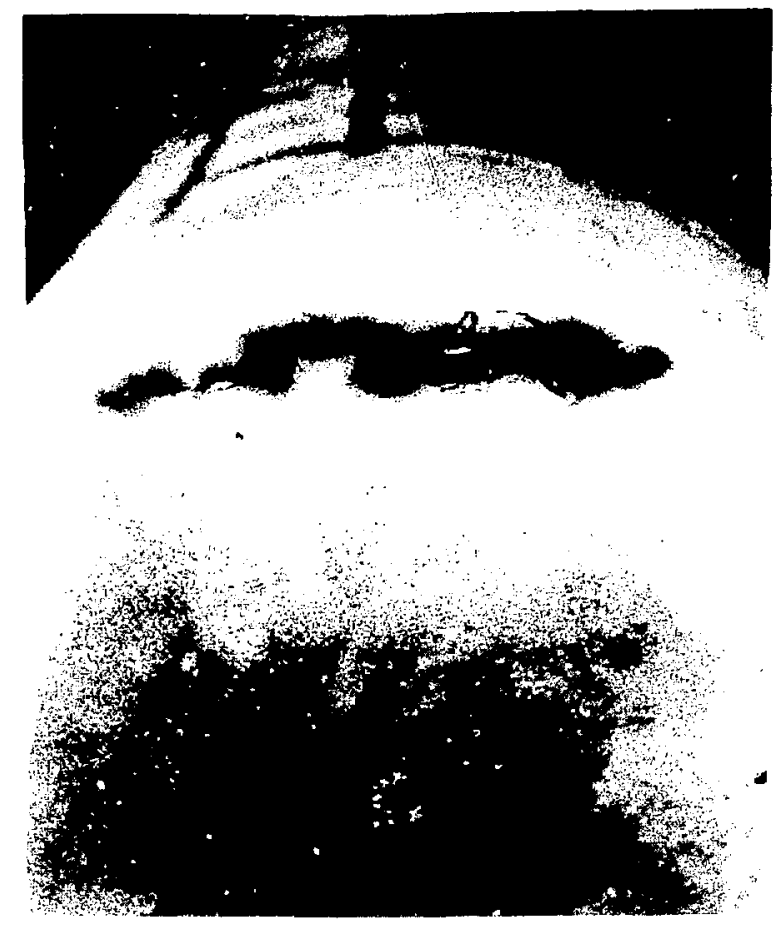

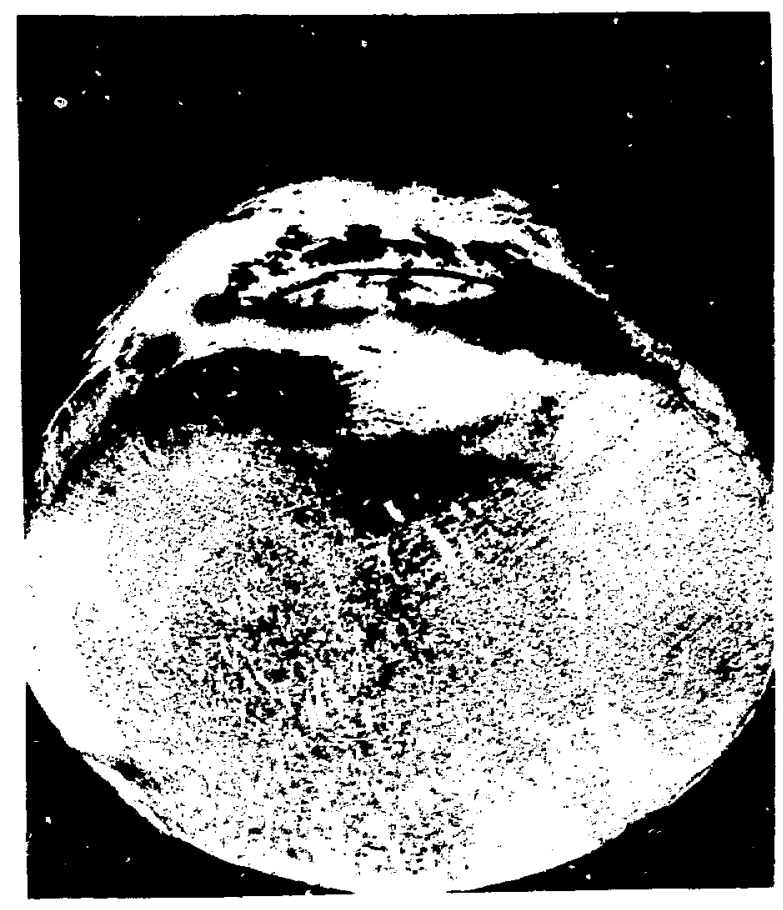

Fig. 15.

Results of posttest dye-penetrant check of botton? weld on Model $B$.
Fig. 16.

Results of posttest dye-penetrant check of bottom weld on Model $C$. 


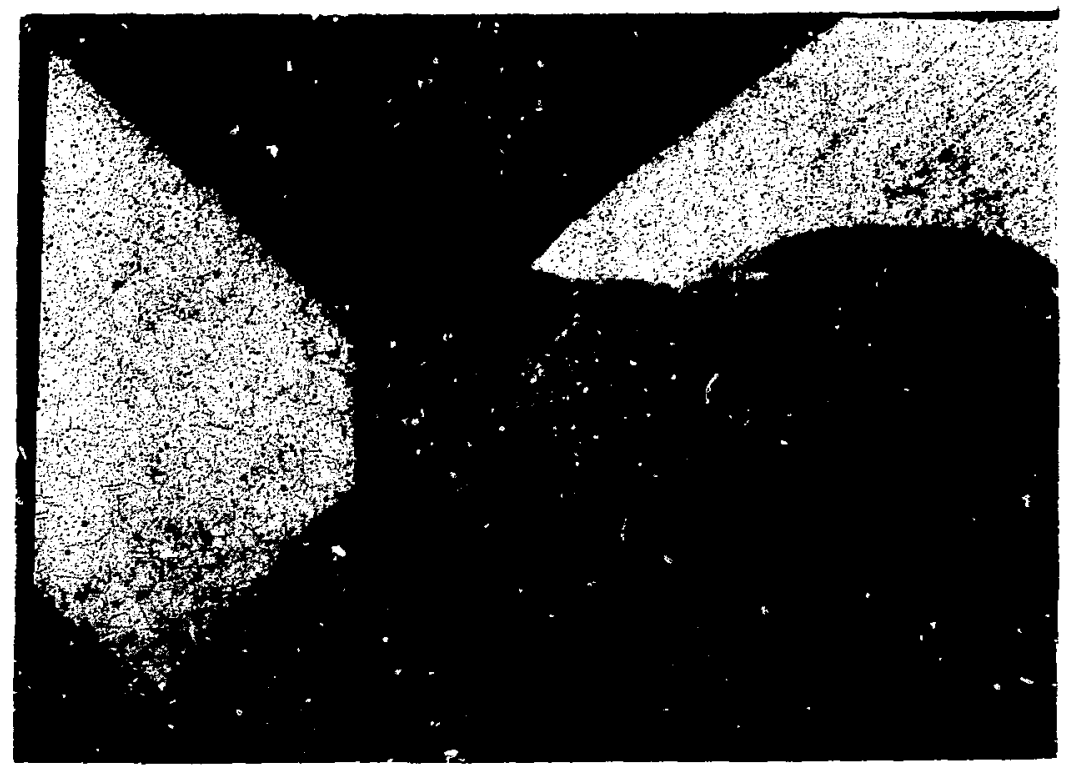

Undisturbed we1d.

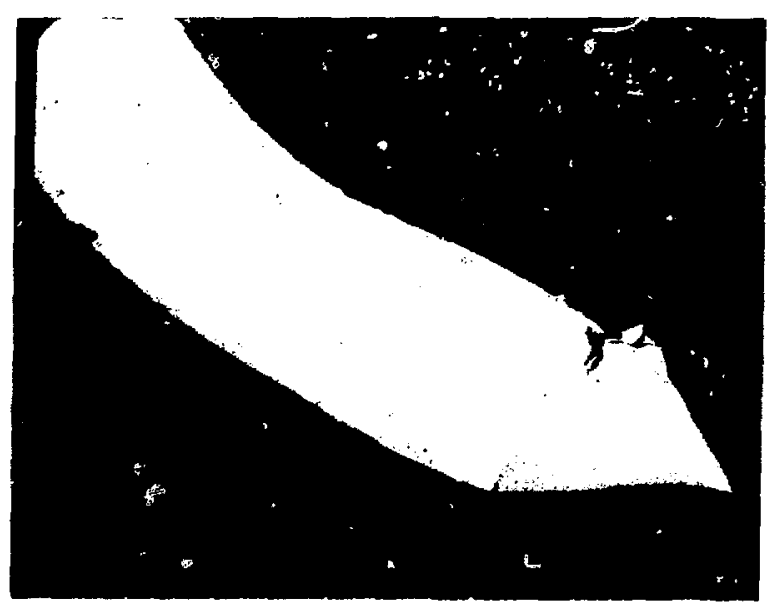

Separated weld (bottom).

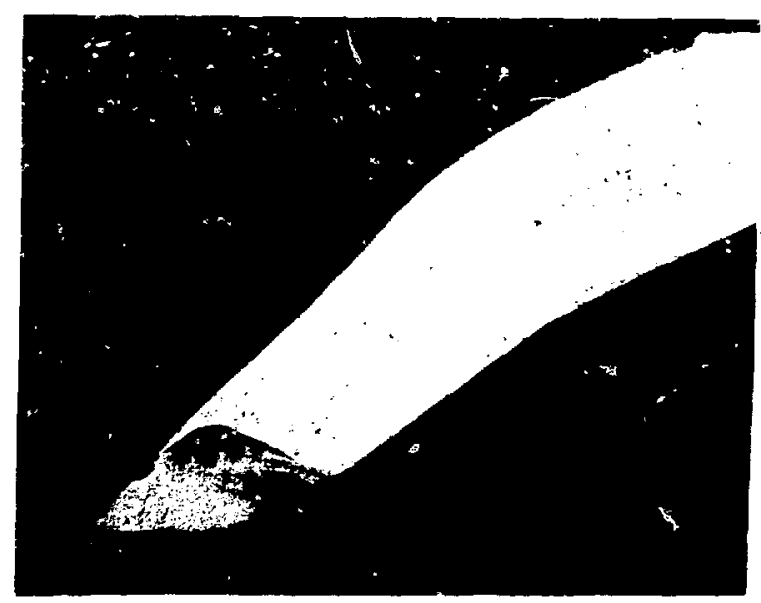

Separated weld (side).

Fig. 17.

Bottom weld damage on Model B. 


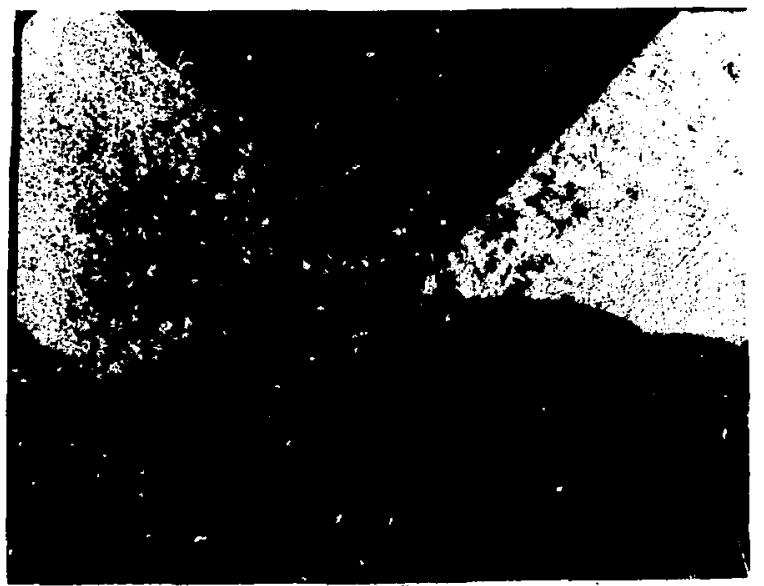

Model A (undisturbed).

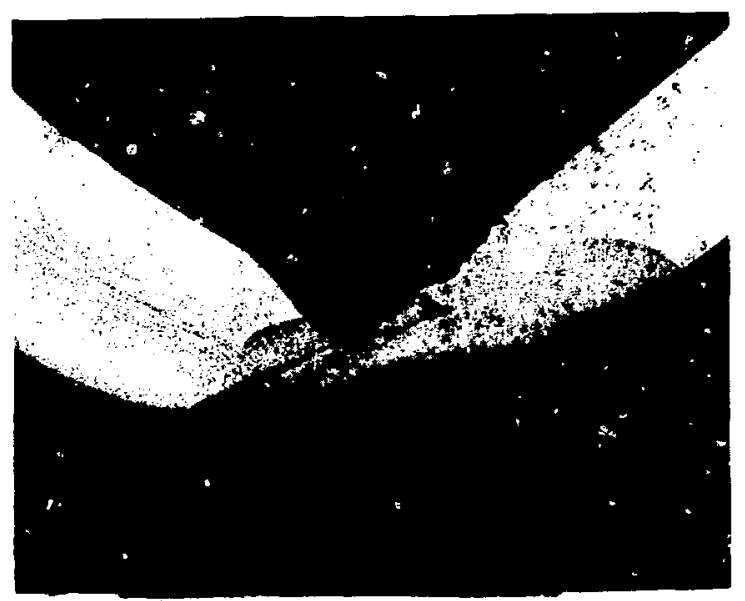

Model A (after impact).

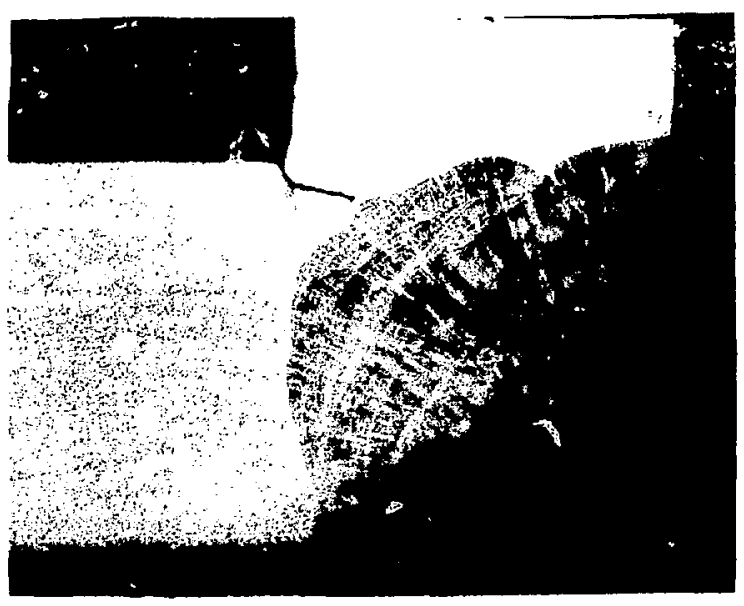

Model C (undisturbed).

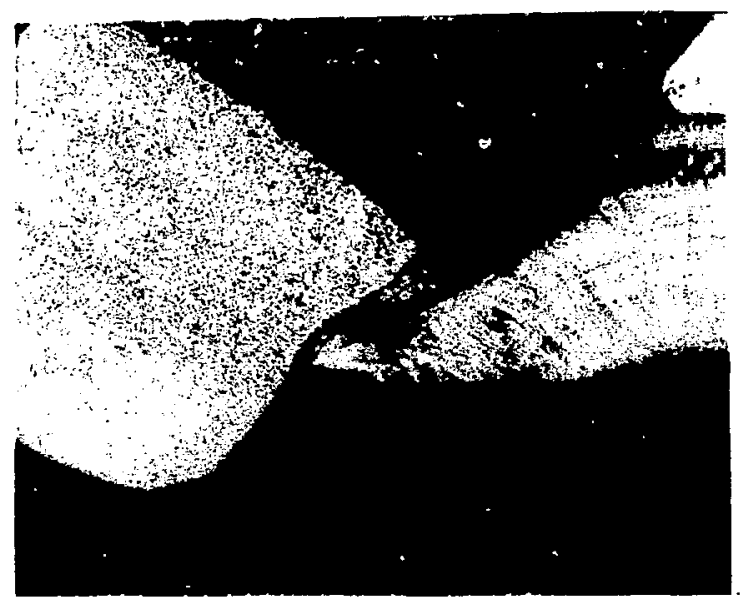

Model C (after impact).

Fig. 18.

Bottom weld damage on Models $A$ and $C$. 


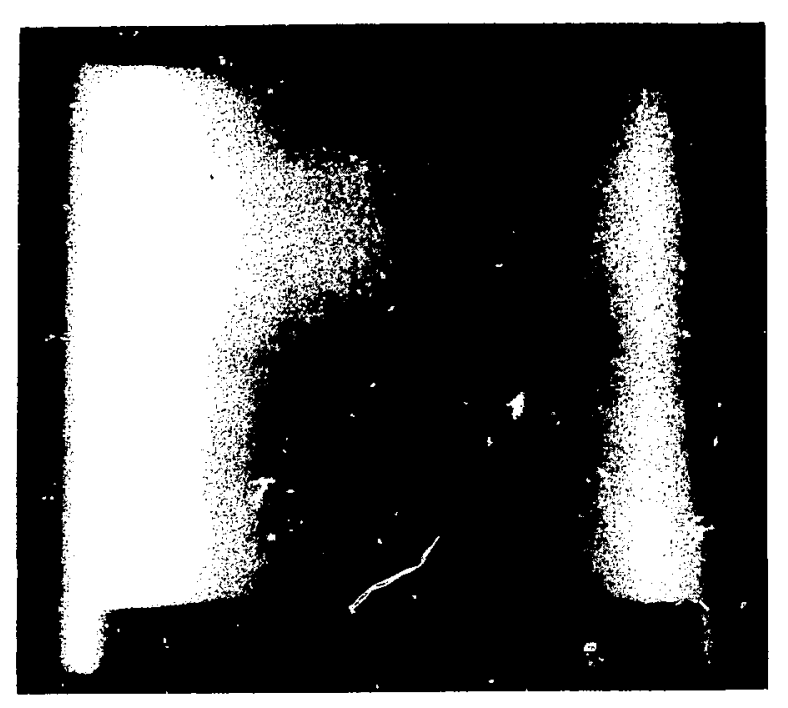

A-1 $\quad 0^{0}$

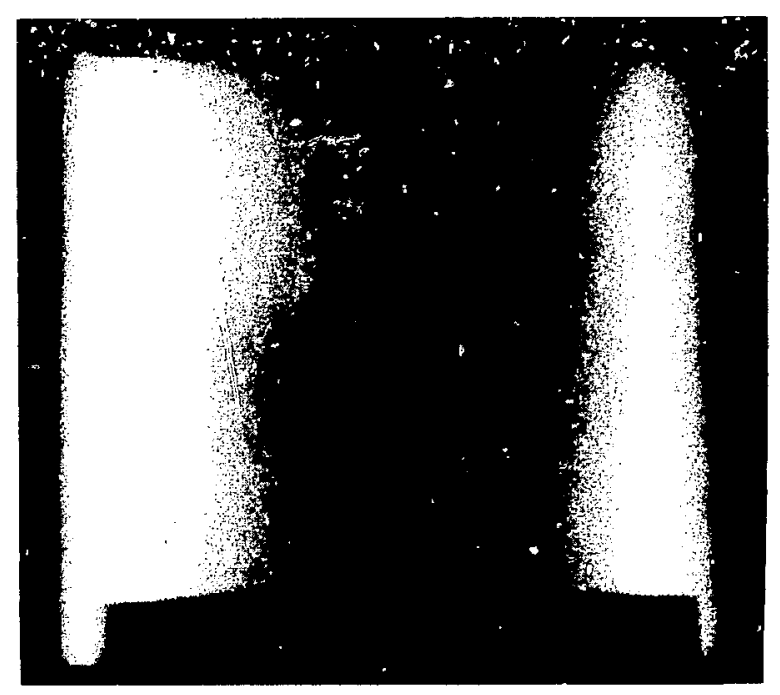

A-1 $90^{\circ}$

Fig. 19.

Radiographs of $\mathrm{U}-2 \mathrm{Mo}_{0}$ bottom seament from Model $A$.

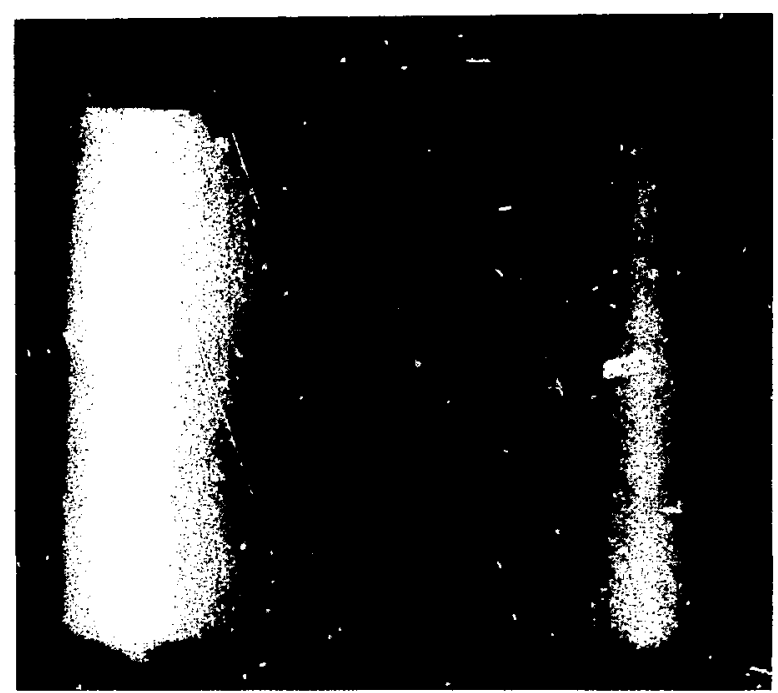

$A-8 \quad 0^{\circ}$

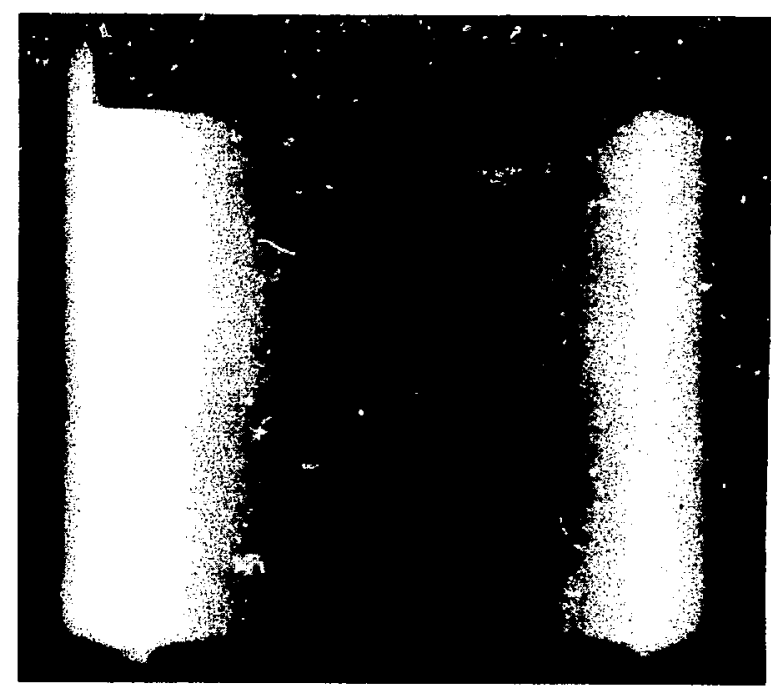

A-8 $90^{\circ}$

Fig. 20.

Radiographs of U-2Mo upper segment from Model A. 


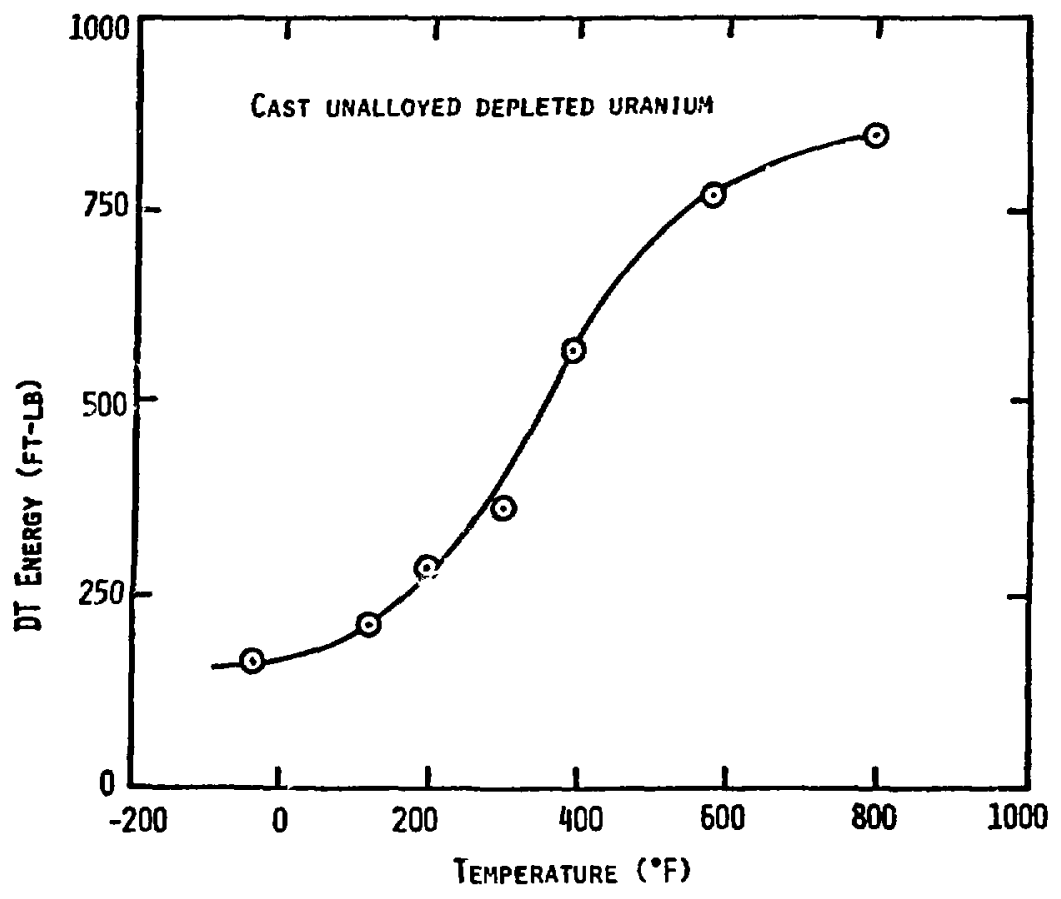

Fig. 27.

Results of Dynamic Tear tests for unalloyed depleted uranium.

\section{REFERENCES}

1. R. J. Burian, W. E. Black, A. A. Lawrence, and M. E. Balmert, "The Validity of Scale Modeling for Large Deformations in Shipping Containers," Battelle Columbus Laboratory report BMI-2040 (October 1979).

2. 0. L. Deel and R. J. Burian, "The Mechanical Properties of Depleted Uranium - 2 w/o Molybdenum Ailoy," Battelle Columbus Laboratory report BMC-2032 (JuTy 1979).

3. E. A. Lange, "Toughness Characterization and Criteria for Steel in Critical Applications," Naval Research Laboratory report NRL-8214 (March 1978).

4. W. S. Pellini, "Principles of Fracture-Safe Design," Reprint from Welding Journal (March and April 1971). 